\title{
Maintaining homeostasis by controlled alternatives for energy distribution in plant cells under changing conditions of supply and demand
}

\author{
Renate Scheibe ${ }^{1}$ (1)
}

Received: 5 June 2018 / Accepted: 6 September 2018 / Published online: 10 September 2018

(c) The Author(s) 2018

\begin{abstract}
Plants depend on light energy for the generation of ATP and reductant as well as on supply of nutrients (inorganic C, N, and $\mathrm{S}$ compounds) to successfully produce biomass. Any excess of reducing power or lack of electron acceptors can lead to the formation of reactive oxygen species (ROS). Multiple systems are operating to avoid imbalances and subsequent oxidative stress by efficiently scavenging any formed ROS. Plants can sense an upcoming imbalance and correspondingly adapt to changed conditions not only by an increase of ROS scavengers, but also by using excess incoming light energy productively for assimilatory processes in actively metabolizing cells of growing leaves. $\mathrm{CO}_{2}$ assimilation in chloroplasts is controlled by various redox-regulated enzymes; their activation state is strictly linked to metabolism due to the effects of small molecules on their actual activation state. Shuttle systems for indirect transfer of reducing equivalents and ATP specifically distribute the energy fluxes between compartments for optimal biomass production. Integration of metabolic and redox signals involves the cytosolic enzyme glyceraldehyde-3-P dehydrogenase (GapC) and some of its many moonlighting functions. Its redoxand metabolite-dependent interactions with the mitochondrial outer membrane, the cytoskeleton, and its occurrence in the nucleus are examples of these additional functions. Induction of the genes required to achieve an optimal response suitable for the respective conditions allows for growth when plants are exposed to different light intensities and nutrient conditions with varying rates of energy input and different assimilatory pathways for its consumption are the required in the long term. A plant-specific respiratory pathway, the alternative oxidase (AOX), functions as a site to convert excess electrons into heat. For acclimation, any imbalance is sensed and elicits signal transduction to induce the required genes. Examples for regulated steps in this sequence of events are given in this review. Continuous adjustment under natural conditions allows for adaptive responses. In contrast, sudden light stress, as employed when analyzing stress responses in lab experiments, frequently results in cell destruction. Knowledge of all the flexible regulatory mechanisms, their responsiveness, and their interdependencies is needed when plant growth is to be engineered to optimize biomass and production of any desired molecules.
\end{abstract}

Keywords Biomass production · Energy metabolism $\cdot$ GAPDH $\cdot$ Glycolysis $\cdot$ Malate valves $\cdot$ Moonlighting $\cdot$ Nitrogen nutrition $\cdot$ Photosynthesis

\begin{tabular}{|c|c|c|c|}
\hline \multicolumn{2}{|c|}{ Abbreviations } & \multirow{2}{*}{$\begin{array}{l}\mathrm{Fd}_{\text {red }} \\
\text { GAPDH }\end{array}$} & \multirow{2}{*}{$\begin{array}{l}\text { Ferredoxin (reduced) } \\
\text { Glyceraldehyde 3-phosphate dehydrogenase }\end{array}$} \\
\hline AOX & Alternative oxidase & & \\
\hline $\mathrm{ADP}$ & Adenosine diphosphate & Glu & Glutamate \\
\hline ATP & Adenosine triphosphate & G6P & Glucose 6-phosphate \\
\hline $\operatorname{COX}$ & Cytochrome $c$ oxidase & G6PDH & Glucose 6-phosphate dehydrogenase \\
\hline \multirow[t]{2}{*}{$\mathrm{CBC}$} & Calvin-Benson cycle & MDH & Malate dehydrogenase \\
\hline & & $\mathrm{NAD}(\mathrm{P})(\mathrm{H})$ & $\begin{array}{l}\text { Nicotinamide adenine dinucleotide (phos- } \\
\text { phate) (reduced) }\end{array}$ \\
\hline \multicolumn{2}{|c|}{$\begin{array}{l}\square \text { Renate Scheibe } \\
\text { scheibe@ biologie.uni-osnabrueck.de }\end{array}$} & $\mathrm{ND}_{\text {in/ex }}$ & $\begin{array}{l}\text { NADH dehydrogenases (internal and } \\
\text { external) }\end{array}$ \\
\hline \multirow{3}{*}{$\begin{array}{l}\mathrm{D} \\
\mathrm{a} \\
4\end{array}$} & \multirow{3}{*}{$\begin{array}{l}\text { Department of Plant Physiology, Faculty of Biology } \\
\text { and Chemistry, University of Osnabrueck, } \\
49069 \text { Osnabrueck, Germany }\end{array}$} & NR & Nitrate reductase \\
\hline & & NiR & Nitrite reductase \\
\hline & & OAA & Oxaloacetate \\
\hline
\end{tabular}




$\begin{array}{ll}\text { OPP } & \text { Oxidative pentose-phosphate } \\ \text { PGA } & \text { 3-phosphoglycerate } \\ \text { PGK } & \text { 3-phosphoglycerate kinase } \\ \text { PET } & \text { Photosynthetic electron transport } \\ \text { RET } & \text { Respiratory electron transport } \\ \text { RuBP } & \text { Ribulose 1,5-bisphosphate } \\ \text { TP } & \text { Triose phosphate } \\ \text { TPT } & \text { Triose-phosphate-phosphate translocator } \\ \text { VDAC } & \text { Voltage-dependent anion channel }\end{array}$

\section{Introduction}

Plants as sessile organisms which depend on light as the primary energy source cannot easily escape stressful conditions. Therefore, their energy metabolism requires permanent adjustment to avoid imbalances and formation of harmful radicals. Particularly the ATP/ADP and NAD(P) $\mathrm{H} / \mathrm{NAD}(\mathrm{P})^{+}$ratios need to be balanced in each cellular compartment as well as the ATP/NADPH ratios therein. In each compartment, specific isoenzymes of basic metabolism provide reductants and ATP, while others consume these energy carriers for assimilation of $\mathrm{C}, \mathrm{N}$, and $\mathrm{S}$ to produce biomass (for review: Scheibe and Dietz 2012). Chloroplasts are the major sites of origin of reducing equivalents and ATP required for assimilatory processes. But on the other hand, chloroplasts and mitochondria are also the source of radicals. Any reactive forms of oxygen and nitrogen (ROS/RNS) resulting from over-reduced electron transport chains are scavenged by multiple antioxidant systems. Since radicals are inevitably formed during metabolic activities, antioxidant systems are present at sufficiently high levels in all compartments which can be enhanced when required (Foyer and Noctor 2011). On the other hand, the early increase of ROS is an important signal to induce systems for defense and repair (Mittler 2016). However, adaptation can also initiate reshuffling of the incoming energy into productive pathways for assimilatory processes. Therefore, it seems to be important to consider the actual conditions in a cell for analysis of productivity and stress responses. Time course and intensity of the applied challenge together with nutrient availability determine whether positive effect or damage is the result of a change of conditions. Sites of energy conversion and distribution as well as the regulatory principles acting in successful adaptive responses are discussed in this review. The Calvin-Benson cycle (CBC), the malate valves, the alternative oxidases, and major steps of reductant generation from the OPP pathway, triose-P oxidation, as well as glycolysis are described as examples for energy fluxes. Components of these major metabolic pathways are tightly linked to sensing of imbalances and initiating responses.

\section{Short-term adaptation to incoming light intensities and protection from oxidative stress}

ROS generation is intimately interlinked with cellular redox-processes in photosynthesis and respiration but does not lead to biomass production. With an excess of incoming energy, the danger of oxidative stress is even increasing. In order to decrease the negative effects, many mechanisms exist in plants and in algae to allow for shortterm responses of the electron flow in the thylakoids when coping with fluctuating input of light. The increase of ROS levels resulting from most types of impact leads to induction of antioxidant activities as part of the general adaptation syndrome first described in medicine for human stress (Selye 1950). Antioxidant enzymes are an essential part of the defense response and do not contribute to biomass production but rather to biomass consumption. As markers that indicate a response to oxidative stress, expression levels of 2-Cys peroxiredoxin (Prx), superoxide dismutase (SOD), and ascorbate peroxidase (APX) or the transcriptional repressor ANAC089 are usually monitored (Pulido et al. 2010; Dietz and Pfannschmidt 2011; Oelze et al. 2012; Klein et al. 2012). Ascorbate and glutathione are generally sufficient as redox buffers for most physiological requirements when changing conditions as fluctuating light or shift of the nutritional status disturb the cellular redox state (Foyer and Noctor 2011). Photoprotection at the cellular level is realized in many ways, starting with the closure of photosystems to decrease the amount of absorbed and excited energy and dissipation of the absorbed energy by a number of mechanisms, e.g., the xanthophyll cycle, state transitions, and contributions of various proteins to cyclic electron flow (Ruban et al. 2012; Hanke and Scheibe 2018; Alric and Johnson 2017). In particular, in lower photosynthetic organisms such as Chlamydomonas or Marchantia, and in cyanobacteria, the contributions from PGR5, PGR5-like, and flavodiiron proteins appear to be essential in particular under fluctuating light conditions (Alric 2010; Allahverdiyeva et al. 2013; Steinbeck et al. 2015; Shimakawa et al. 2017; Jokel et al. 2018). Faster recovery from the protected states in fluctuating light was suggested to help improve yield (Kromdijk et al. 2016). The repair machinery for the D1 protein prevents damage at this crucial point after energy capture in the reactive center of photosystem II (Theis and Schroda 2016). If the environmental change, however, is as substantial as to overstress the cell's defense and repair mechanisms, an increase of ROS will be detectable as a result of "oxidative stress," finally leading to cell death and necrosis. 
When light-generated reductants are not used, the removal of energized electrons via water-water cycles (Beck/Halliwell/Asada pathway or NTRC/peroxiredoxin), photorespiration, or alternative oxidase (AOX) avoids radical formation in the electron transport chains both in chloroplasts and mitochondria (Scheibe et al. 2005; Sunil et al. 2013; Voss et al. 2013). The antioxidant systems need NADPH for regeneration provided by linear electron flow. Through the OPP pathways, both in plastids and cytosol, an alternative source for NADPH by carbohydrate oxidation is available in plants when required during dark metabolism. An electron acceptor limitation at PSI due to the lack of the major ferredoxin $(\mathrm{Fd} 2)$ in a knockout line of Arabidopsis leads to insufficient rates of reductant generation and even results in oxidative activation of the plastidial G6PDH in the light (Voss et al. 2008). In mitochondria, NADP-isocitrate dehydrogenase provides reductant for the NTR system (Møller 2001).

\section{Rapid flux adjustments by post-translational regulation of chloroplast enzymes}

Various steps in the Calvin-Benson cycle (CBC) are controlled by light/dark-modulated enzymes (Buchanan and Balmer 2005) to maintain homeostasis even under changing conditions. For reversible mediation of redox modifications to the various target proteins, a large number of thioredoxins and glutaredoxins are present in each compartment (Meyer et al. 2008). Metabolism determines the actual flux through the respective step by changing the rates of the redox interconversions between reduced and oxidized forms of these enzymes individually (Scheibe 1991). On the one hand, this mechanism allows for diurnally separated fluxes through reductive and oxidative pentose-phosphate cycle, respectively. But most importantly, continuous adjustment of enzyme activities is possible during illumination (Scheibe 1991; Knuesting and Scheibe 2018). As a key step of the $\mathrm{CBC}$, the heterotetrameric isoform of GAPDH $(\mathrm{GapA} / \mathrm{B})$ is redox- and metabolite-controlled in its light/dark modulation (Baalmann et al. 1995, 1996). Both, reduced thioredoxin and the substrate 1,3bisPGA, determine the active portion of the enzyme required for the actual flux. As another example, the stromal FBPase activity is strictly following the demand as communicated by rising stromal concentrations of the substrate FBP. In addition to its role as a substrate, FBP functions as a positive effector for reductive activation of FBPase, and as the inhibitor of oxidative inactivation, with both effects acting on the redox-cycle resulting in the required enzyme activity at any time at this step of the CBC (Scheibe 1991). On the other hand, the lack of electron acceptor and an increased NADPH level (i.e., a low concentration of the inhibitor $\mathrm{NADP}^{+}$) causes the malate valve to open via reductive activation of the NADP-dependent malate dehydrogenase (NADP-MDH) for indirect export of NADPH in illuminated chloroplasts. In contrast, if reducing equivalents are consumed for 3-PGA reduction, the higher $\mathrm{NADP}^{+} /\left[\mathrm{NADPH}+\mathrm{NADP}^{+}\right]$ratio inhibits NADP-MDH activation and prevents export of reducing equivalents from the chloroplasts (Scheibe 2004).

Such autoregulatory mechanism is making use of substrates or products of an enzyme for fine-tuning its activity specifically, thus supporting homeostasis of metabolism even under changing conditions (Faske et al. 1995; Holtgrefe et al. 1997). The hierarchy of the various electron acceptors is evident in experiments with isolated chloroplasts under defined metabolic conditions (Backhausen et al. 1994, 2000). $\mathrm{CO}_{2}$ assimilation as the major reductive pathway is continuously fed with energy, but any sulfate or nitrite will be reduced directly with $\mathrm{Fd}_{\text {red }}$ prior to NADPH generation. Enzyme regulation allows for adaptation of the plant to cope with an increased energy input and usage of electrons preferentially for biomass production. An increase of the light intensity immediately leads to some over-reduction of the components of the electron transport chain, and the system responds with oscillations that are dampened due to the changed enzyme activities to reach a new steady state. The rapid activation of NADP-MDH and a subsequent decrease of activity when the redox balance has been re-established prevents any severe imbalances (Scheibe and Stitt 1988). Similar responses adjust the fluxes through the various parts of the CBC. Such rapid responses, however, are only possible due to the post-translational modification of enzymes that are already present. Increased enzyme levels can only be achieved by gene transcription and translation requiring more time (see "Moonlighting and multitasking of enzymes involved in energy metabolism" section).

\section{Distribution of assimilates and energy across compartment borders}

The primary products of carbon assimilation are the triose phosphates (TP). Five out of six molecules produced during three $\mathrm{CBC}$ turnovers are used for the regeneration of the $\mathrm{CO}_{2}$ acceptor ribulose 1,5-bisphosphate (RuBP), while every sixth one is a net product and can be partitioned either into transitory starch or into sucrose synthesis in the cytosol after TP export. The TP-phosphate translocator (TPT) functions as an antiporter, shuttling TP in exchange with inorganic phosphate $\left(\mathrm{P}_{\mathrm{i}}\right)$ or 3-phosphoglycerate (3-PGA), the direction depending on the actual metabolic fluxes (Flügge and Heldt 1984) (Fig. 1). Export of TP can be linked to the indirect export of NADPH and ATP, and, therefore, it can also serve as another means for shuffling energy across membranes for the supply of neighboring compartments. The release of 
Fig. 1 Generation and indirect transport of reducing equivalents and ATP. Excess NADPH from the light reactions, not needed for stromal metabolism, e.g., CBC, or for balancing the ATP/NADPH ratio, is transformed to malate by the light/ dark-modulated NADP-dependent malate dehydrogenase (NADP-MDH). Malate can be used to generate NADH in the cytosol or ATP in the mitochondria. When NADPH is needed as a reductant in the cytosol, either the irreversible GapN (non-phosphorylating GAPDH) or the oxidative pentose-phosphate (OPP) pathway oxidize assimilates (TP or G6P) for the sake of protection from oxidative stress, defense, and repair

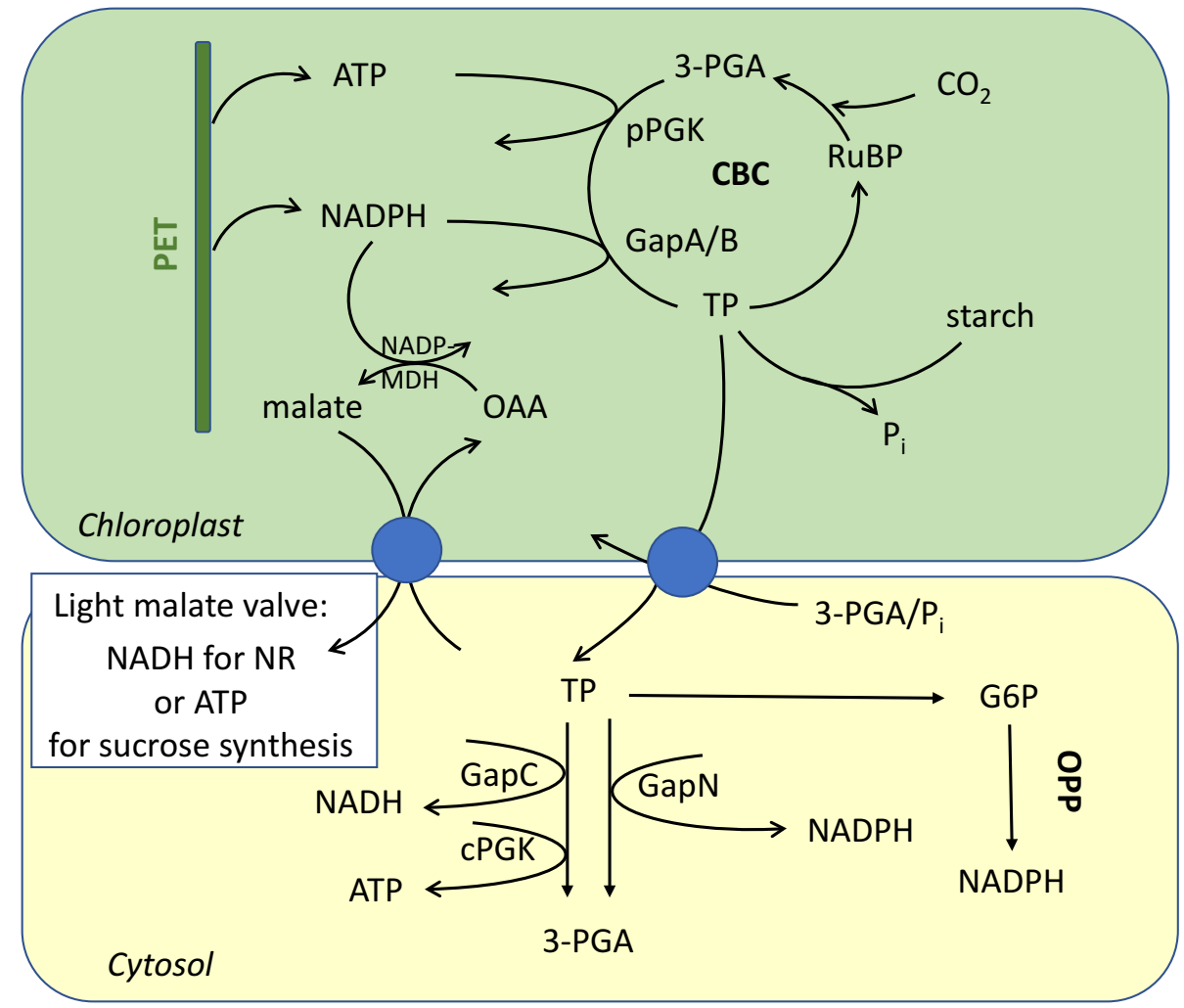

the indirectly transported energy can occur in the glycolytic steps catalyzed by cytosolic NAD-GAPDH (in plants GapC) and 3-phosphoglycerate kinase (PGK) to provide NADH and ATP for cytosolic metabolism. Alternatively, a plantspecific glyceraldehyde 3-phosphate dehydrogenase (GapN) catalyzes an irreversible oxidation of the aldehyde (TP) to yield the acid 3-PGA without coupling the oxidation with substrate phosphorylation and ATP generation (Fig. 1). Such indirect export of reductant from the chloroplast appears to be used when neither ATP nor NADPH are consumed in plastidial metabolism, e.g., due to the lack of $\mathrm{CO}_{2}$ during drought stress (Bustos et al. 2008). As expected, the lack of GapN in knockout plants leads to an increased expression of the cytosolic G6PDH isoforms 5 and 6 (Rius et al. 2006). In plants, NADPH can thus be formed from oxidation of glucose-6-P (G6P) or triose-P (TP), respectively, by cytosolic glucose 6-phosphate dehydrogenase (G6PDH) and, specifically in plants, by non-phosphorylating GAPDH (GapN). GapN has been shown to be rather stable under oxidizing conditions (Piattoni et al. 2013). An increased G6PDH or GapN activity, therefore, enables maintenance of redox homeostasis before any oxidative damage would occur during short-term stress (Landi et al. 2016).

Although cytosolic enzymes are potential sources of NADH and ATP (glycolytic step catalyzed by GapC/ PGK, and by NAD-malic enzyme), provision of NADH for nitrate reduction and of ATP for sucrose synthesis through interorganellar transport originating from chloroplasts and mitochondria, respectively, has been shown to be necessary for net production (Gardeström and Igamberdiev 2016; Scheibe 2004; Krömer and Heldt 1991). As described in "Rapid flux adjustments by post-translational regulation of chloroplast enzymes" section, the chloroplast NADP-MDH as part of the malate valve operating in the light for export of excess NADPH is strictly controlled by the $\mathrm{NADP}^{+}$-to-NADPH ratio acting on the redox-cycle between reduced and oxidized enzyme form driven by the ferredoxin-thioredoxin system and the concomitant reoxidation of the enzyme. It allows for indirect export of reducing equivalents only when they are in excess (Scheibe 2004). Malate can then be used in many ways in the various compartments that possess MDH activities of the NAD-dependent isoforms. The relevant membranes are equipped with the specific dicarboxylate transporters that operate along the concentration gradient determined by production and consumption on each (Selinski and Scheibe 2018).

A different type of malate valve to maintain redox balance in plastids of non-green cells or in chloroplasts in the absence of light could be identified. NADH generated in the glycolytic step by the plastidial NAD-GAPDH (GapCp in A. thaliana) will be converted by a plastidial NAD-MDH resulting in the so-called dark malate valve (Backhausen et al. 1998b; Scheibe 2004) (Fig. 1). For 
metabolic processes, therefore, NADPH (from glucose 6-P (G6P) in the plastidial oxidative pentose-phosphate (OPP) pathway) and ATP (from substrate phosphorylation in plastidial glycolysis) are generated independently at the required rates.

The interplay between light reactions and mitochondrial metabolism has been suggested to play an important role to optimize photosynthesis (Raghavendra and Padmasree 2003). The particular role of AOX in avoidance of ROS formation under conditions such as high light or drought (lack of acceptor $\mathrm{CO}_{2}$ ) has been demonstrated in transgenic lines lacking the major isoform of the alternative oxidase AOX1A (Strodtkötter et al. 2009). AOX1A is required for the controlled release of unused electrons under high light intensities. An increased expression of AOX1D does not entirely alleviate the lack of AOX1A in the mutant plants. The specific fine-tuning of the activity of each AOX isoform appears to be achieved at multiple levels, including the post-translational modifications of the reduced (activated) proteins by specific tricarboxylic acid cycle intermediates (Selinski et al. 2017, 2018a). Again, metabolites determine the activities of a valve to release any excess reducing power that has not been used elsewhere in the cell as heat only when indicated by changing metabolite pools (Selinski et al. 2018b). In this sense, AOX activities are determined by redox state and mitochondrial metabolism, and they act as a sensor of imbalances due to the regulatory properties of this valve functioning for the final non-destructive dissipation of excess electrons as thermal energy.

\section{Energy distribution according to kind and availability of nitrogen source}

Not only the availability of light and $\mathrm{CO}_{2}$, but also the type of $\mathrm{N}$-source, whether nitrate or ammonium as a nutrient, is a challenge for plants. Although nitrate is the preferred nitrogen source, ammonium can also be assimilated since the required enzymes are present due to the photorespiratory $\mathrm{NH}_{4}{ }^{+}$re-assimilation in all C3-plants. $\mathrm{N}$-assimilation can take place either in green tissues or directly in root cells (Fig. 2). Photorespiration itself with its energy-consuming glycollate detoxification pathway provides another option for buffering and rebalancing the energy status during stress (Wingler et al. 2000; Hodges et al. 2016).

Integration and cooperation of these metabolic activities pose some problems, since energy carriers required in the various cellular compartments need to be shuttled indirectly across membranes (Scheibe 2004; Taniguchi and Miyake 2012). In the absence of photosynthesis, electrons are made available by carbohydrate oxidation (glycolysis or OPP pathway) (Hansen et al. 1998). Therefore, the aspects of macroand micro-compartmentation need to be taken into account as already mentioned in the context of $\mathrm{CO}_{2}$ assimilation. Metabolite transporters, as well as the formation of metabolons, facilitate such complex metabolic networks (Sweetlove and Fernie 2013).

The requirement for reductants and ATP differs considerably, also as the sites of usage are concerned, when shortterm or long-term exclusive ammonium supply needs to be coped with (Fig. 2). Short ammonium exposure (3 h) of
Fig. 2 Energy requirements for $\mathrm{N}$-assimilation as dependent on the $\mathrm{N}$-source. Nitrate and ammonium assimilation require different kinds of reductant and ATP in the various compartments. Balancing of the ATP/ $\mathrm{NAD}(\mathrm{P}) \mathrm{H}$ ratio and indirect transport of the energy carriers as necessary in light and dark is achieved by the provision of reduced ferredoxin $\left(\mathrm{Fd}_{\text {red }}\right)$, $\mathrm{NADPH}, \mathrm{ATP}$, and NADH for the respective isoenzymes. In darkened chloroplasts or non-green plastids, ATP and $\mathrm{Fd}_{\text {red }}$ are obtained via plastidial glycolysis at the substrate phosphorylation step of plastidial NAD-GAPDH (GapCp) in conjunction with the plastidial OPP pathway and the dark malate valve

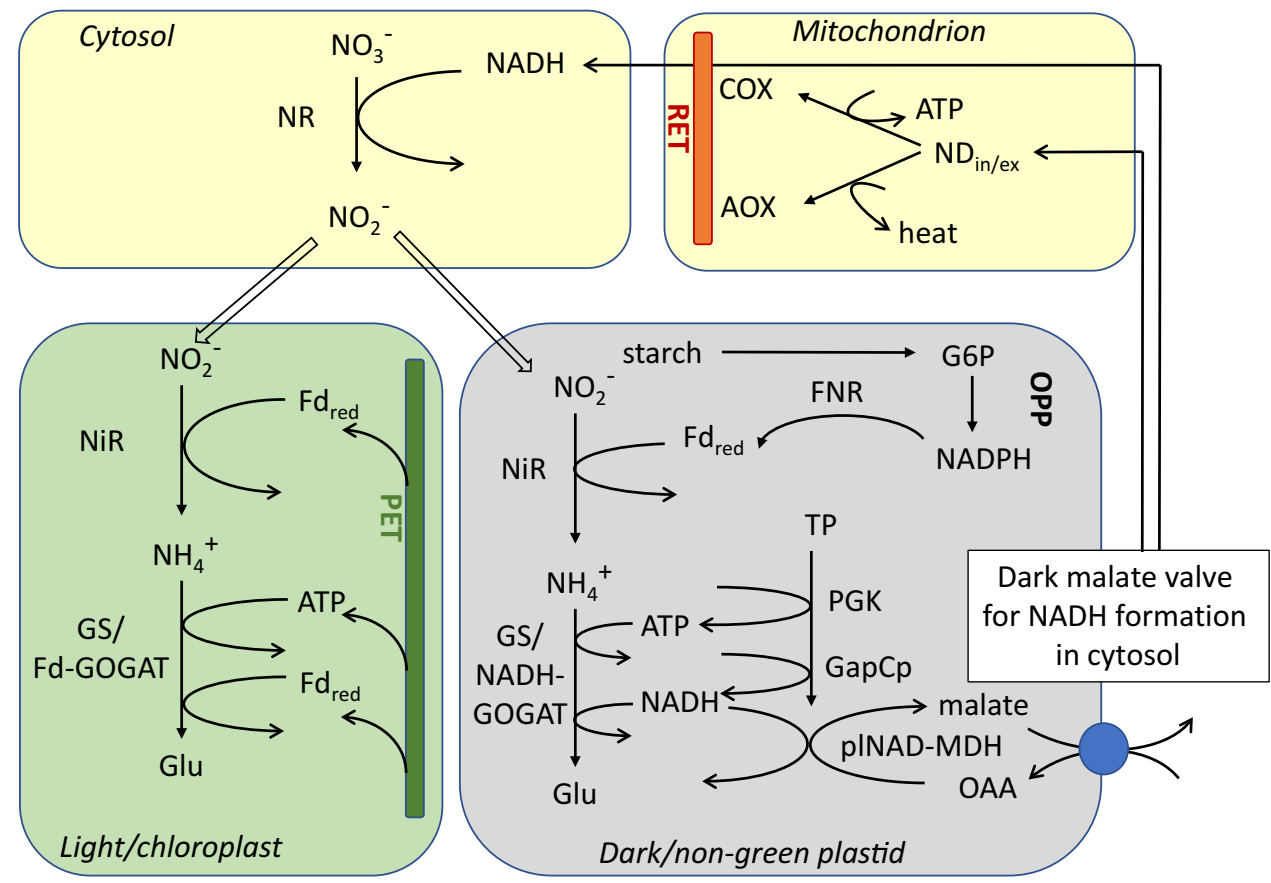


Arabidopsis plants grown originally on nitrate resulted in a fast response to achieve protection from oxidative stress (Podgórska et al. 2017), with increases in antioxidative enzymes, such as CuZn-SOD, and induction of alternative electron transport pathways in mitochondria (Escobar et al. 2006). Under these conditions, less reductant is needed and is dissipated via AOX to prevent radical formation. Upon a long-term exposure, ammonium causes adverse effects on the cellular redox balance and the adenylation status, mainly in the extrachloroplastic fraction, and on mitochondrial ROS production, resulting in massive growth retardation, but chloroplasts appeared to remain functional (Podgórska et al. 2013). As an increased NADH-GOGAT is necessary for successful $\mathrm{NH}_{4}{ }^{+}$assimilation (Konishi et al. 2014), Arabidopsis plants with a decreased expression of the plastidial NADdependent MDH (plNAD-MDH) could survive growth on ammonium better than the wild type, due to a compensatory increase of NADH-GOGAT (Selinski and Scheibe 2014). Interestingly, plants lacking the complex I in the respiratory electron transport chain in mitochondria (frostbitel) also exhibited improved growth on ammonium compared to nitrate (Podgórska et al. 2015).

Under nitrate nutrition, requirements for reductant and ATP supply differ entirely from ammonium conditions (Fig. 2) (Escobar et al. 2006). In particular, large amounts of electrons are required in the plastids for nitrite reduction. In green cells, provision of plastidial reductants results from photosynthetic electron flow taking electrons from reduced ferredoxin $\left(\mathrm{Fd}_{\mathrm{red}}\right)$ directly. In non-photosynthetic conditions, NADPH generated in the plastidial OPP pathway together with ferredoxin-NADP oxidoreductase (FNR) to reduce the root ferredoxins is required. Indeed, expression levels of the plastidial isoforms of glucose 6-phosphate dehydrogenase (G6PDH2 and 3) are increased in roots and shoots of nitrate-grown plants (Wang et al. 2003; Bussell et al. 2013). Knockout plants for NADP-MDH compensate the lack of the malate valve with increased expression of alternative systems for reductant dissipation but exhibit improved growth on nitrate as $\mathrm{N}$-source when compared to wild type (Hebbelmann et al. 2012). Taken together, the lack of malate valves for export of NADH and of NADPH from plastids in darkness or during illumination, respectively, leads to a shift in reductant availability that improves either $\mathrm{NH}_{4}{ }^{+}$ or $\mathrm{NO}_{3}{ }^{-}$assimilation compared to wild type (Selinski and Scheibe 2014).

\section{Moonlighting and multitasking of enzymes involved in energy metabolism}

A complex network of reactions during primary metabolism is characterized by multiple control points for flexible integration and adjustment of fluxes dependent on supply and demand in accordance with changing environmental conditions. Sustained environmental stress factors, e.g., shortage of nutrients and the presence of abiotic stressors affecting developmental programs, are perceived and responded to through altered gene expression when the capacities of the regulated enzymes are exhausted. Input signals (redox state and metabolite levels) generated from a change of conditions or the incidence of different types of stress are integrated to yield very specific answers. Responses at all levels of regulation and over the total time span after application of an environmental change such as increase of light intensity become evident (Dietz 2015).

The glycolytic enzyme GAPDH (GapC1 and 2 in $A$. thaliana), as well as aldolase, is subject to modulation by the redox status of the cytosol, namely by S-glutathionylation and S-nitrosylation of their cysteine residues, resulting in reversible or irreversible inactivation, depending upon the presence of substrate that prevents the inactivation (Holtgrefe et al. 2008; van der Linde et al. 2011). A role of glycolytic enzymes such as GAPDH has been suggested already as a redox sensor for $\mathrm{H}_{2} \mathrm{O}_{2}$ increase (Hancock et al. 2006). There is now a growing number of publications describing the "moonlighting" properties of enzymes involved in central energy metabolism, namely the cytosolic glyceraldehyde-3-P dehydrogenase (NADGAPDH, GapC in plants), in all organisms (Sirover 2011; Hildebrandt et al. 2015). Redox-dependent association of GAPDH with mitochondria was suggested to induce improved energy generation. We found these glycolytic enzymes associated with the actin cytoskeleton and with mitochondria attached via the voltage-dependent anion channel (VDAC) (Wojtera-Kwiczor et al. 2012; Schneider et al. 2018). The redox-dependent change of the properties of the modified protein is the basis for changes in activity, subcellular localization, and protein-protein interactions in the context of many more cellular responses yet to be identified. As a target of $\mathrm{H}_{2} \mathrm{O}_{2}$, cytosolic GAPDH has been suggested to mediate any redox imbalance in a signaling cascade to induce antioxidant defense (Hancock et al. 2005). The high sensitivity of the catalytic cysteine residue present in the active site of GAPDH towards oxidation provides the basis for its prominent role as a central regulator (Peralta et al. 2015; Zaffagnini et al. 2016). There are some evidences that redox-imbalances trigger the nuclear localization of GapC (Schneider et al. 2018). As a wellstudied example in the mammalian system, an association of S-nitrosylated GAPDH with SIAH1, an E3-ubiquitin ligase, leads to nuclear translocation and induction of cell death (Hara et al. 2005). In fact, a similar protein, namely SINAL7, was identified as a binding partner of GAPDH in plants (Peralta et al. 2016), suggesting moonlighting functions of the metabolic enzymes in plants as also evidenced in yeast and animals. Furthermore, cytosolic GAPDH was 
detected in nuclei of cadmium-treated roots (Vescovi et al. 2013).

With the aim to identify cis-elements and proteins of the transcriptional machinery involved in the induction of NADP-MDH expression as seen under high light in shortday-grown plants (Becker et al. 2006), we have performed a yeast-one-hybrid screen with gene fragments of the NADPMDH gene. Interestingly, the glycolytic enzymes GapC and aldolase were identified as prominent binding partners of these fragments comprising parts of the coding sequence and an intron (Hameister et al. 2007). We could show that under conditions of excessive illumination, NADP-MDH transcript is increased, but only in actively metabolizing cells in leaves of vegetatively growing plants under shortday photoperiod (8 h light, $16 \mathrm{~h}$ dark) (Becker et al. 2006). In contrast, plants grown under long-day photoperiod that are flowering-induced and aim for finishing their life cycle as soon as possible with seed production induce only protective mechanisms for ROS scavenging, but not NADP-MDH expression. Consequently, the highest capacities of NADP$\mathrm{MDH}$ were found in growing leaves of young tobacco plants (Faske et al. 1997; Backhausen and Scheibe 1999). The assumption that NADP-MDH contributes to improved growth was also confirmed when potato plants that overexpress NADP-MDH were found to grow faster than antisense plants when they were kept under ambient (e.g., fluctuating light) conditions (Backhausen et al. 1998a). Imbalances in the photosynthetic electron transport chain lead to a signal transfer via oxidation of cytosolic GAPDH and its nuclear translocation to activate transcription of NADP-MDH (Zachgo et al. 2013; Hildebrandt et al. 2015). When grown in long-day photoperiod (as is usually the case when rapid growth and reproduction are the primary aims of experimental plant cultivation), protection from oxidative stress or cell death is induced upon environmental challenges, and no further acclimation or improvement of metabolism is observed.

The various isoforms of MDH present in all compartments together with dicarboxylate translocators of the organellar membranes allow for interorganellar communication (Selinski and Scheibe 2018). In this respect, a central role of peroxisomal NAD-MDH is suggested for interorganellar communication in Chlamydomonas (Kong et al. 2018). Interestingly, as is known for GapC, cytosolic NAD-MDH1 appears to be subject to redox modifications as well (Hara et al. 2006), and the reversible oxidation of its C-terminal cysteine residue might help to protect the enzyme from oxidative damage (Huang et al. 2017). Redox-dependent signaling and effects on gene expression might, therefore, also derive from imbalances between the compartments, sensed by the involved enzymes and transferred to the nucleus. Upon redox-imbalances and ROS formation due to stress impact, plants can adapt and acclimate to various stress factors resulting even in cross-tolerance (Locato et al. 2018).
Malate itself has now been suggested to serve as a signal in cases of imbalances between chloroplast and mitochondria (Zhao et al. 2018). Malate as a signal and the nucleo-cytosolic occurrence of NAD-MDH are most likely indicators for redox-imbalances not only in plants, but also in mammalian cells when adaptation to metabolic imbalances is required and p53 transcriptional activity is induced upon metabolic stress (Lee et al. 2009).

\section{Redox-regulation at all levels for optimal adaption of energy metabolism}

In addition to causing oxidative stress and damage, ROS/ RNS can cause oxidative cysteine modifications such as the reversible formation of disulfide bridges, S-glutathionylation, and S-nitrosylation found to occur at various target proteins. These post-translational redox modifications are components of regulatory systems on the one hand controlling enzyme activities diurnally as on/off switches, and during illumination by fine-tuning of light-dark modulation of chloroplast enzymes (Scheibe 1991; Knuesting and Scheibe 2018). On the other hand, when cytosolic enzymes of central energy metabolism are affected upon a shift towards oxidizing conditions, they act in signal transduction pathways involved in transcriptional regulation (Zachgo et al. 2013; Hildebrandt et al. 2015). For such cases of regulation, ROS are good (Mittler 2016).

Light-dark modulation and fine-tuning by metabolites in the case of the thioredoxin-dependent of reversible redox modifications of preexisting chloroplast enzymes allows for fast responses to changing conditions, but only within the range of activity that is limited by its presently available full capacity ( $100 \%$ of its activity). However, sustained demand for the full capacity results in induction of gene expression and the increased synthesis of the limiting enzyme. Since the respective chloroplast enzymes are nuclear encoded, retrograde signaling from the chloroplast to the nucleus has to be assumed. This scenario requires a signal to be transferred through the cytosol. Since apparently, posttranslational redox modifications affecting activities are not only observed in chloroplasts but also in other cellular compartments, such signal can be transduced to the cytosol. Concerning the glycolytic enzymes in the cytosol, not only their activities but also their subcellular localizations and binding properties are modified allowing for their moonlighting functions. Enzymes of central energy metabolisms such as GapC or cytosolic MDH act as sensors to integrate incoming information on the actual energy status. The output allows for adjustment of metabolic fluxes to variable conditions. Therefore, GapC and cytosolic MDH are central not only as part of the energy fluxes but also as hubs to link redox state and energy-requiring metabolism in this highly 
complex network. Oxidative inactivation by modification of sensitive cysteine residues can elicit changes in energy metabolism depending on the general situation of the cell. At both ends, namely in chloroplasts and in mitochondria, malate valve and AOX, respectively, respond directly to and can also be seen as sensors of energy status for maintenance of homeostasis.

\section{Conclusions and outlook}

Plants possess the capability to avoid imbalances or any significant increase in ROS. In most situations which are not destructive, cellular homeostasis is maintained over a wide range of conditions. Under optimal conditions in nature, and in carefully controlled experimental setups, the changed protein-protein interactions and localizations of GapC causative for induction of the respective genes result in sustained or even increased biomass production and avoidance of oxidative stress. A sudden, massive change of light intensity, however, leading to a more pronounced and eventually toxic increase of ROS, induces transcription of defense genes, or programmed cell death, or leads to uncontrolled damage and necrosis. The signal transduction networks of plants are highly complex due to their ability to integrate multiple kinds of information for a proper response. In this challenging situation, metabolism and redox homeostasis permanently require adjustment and optimization (Kocsy et al. 2013; Mittler 2016; Foyer et al. 2017a). Cytosolic GAPDH and the isoforms of MDH and AOX as control hubs during active metabolism are capable to sense and mediate incoming challenges.

The role of GapC in improving biomass production by redirecting energy fluxes according to the light and nutrient availability requires analysis of mechanisms at multiple regulatory levels. To improve productivity by increasing the efficiency of photosynthesis, the aspect of adaptation and the required signals and time span to realize an altered machinery for flexible responses need to be taken into consideration (Foyer et al. 2017b; Bailey-Serres et al. 2018). It is crucial to obtain a better understanding of the interaction of the various mechanisms that help to fine-tune the responses of plant cells to changing environments, when aiming for "better plants" to be created by biotechnological approaches (Kramer and Evans 2011; Kerchev et al. 2015). Any breeding or biotechnological approaches aiming for a productive outcome should have in mind the complex regulatory network to avoid failure of seemingly straight-forward approaches. The actual situation in a cell or plant is determined by its redox state (normal or stressed) and its metabolic status (fasting and feeding). Failure of the coordination of nutritional status with growth activities is detrimental to the success in biomass production (Dietz et al. 2010; Dolferus 2014).

Acknowledgements Financial support from the DFG Research Unit SPP 1710 (SCHE 217/16) as well as continued funding in previous years is gratefully acknowledged. Thanks are due to Dr. J. Selinski (Latrobe University, Melbourne) and Dr. J. Knuesting (University of Osnabrueck) for critical reading of the manuscript.

Open Access This article is distributed under the terms of the Creative Commons Attribution 4.0 International License (http://creativeco mmons.org/licenses/by/4.0/), which permits unrestricted use, distribution, and reproduction in any medium, provided you give appropriate credit to the original author(s) and the source, provide a link to the Creative Commons license, and indicate if changes were made.

\section{References}

Allahverdiyeva Y, Mustila H, Ermakova M, Bersanini L, Richaud P, Ajlani G, Battchikova N, Cournac L, Aro EM (2013) Flavodiiron proteins Flv1 and Flv3 enable cyanobacterial growth and photosynthesis under fluctuating light. Proc Natl Acad Sci USA 110:4111-4116. https://doi.org/10.1073/pnas.1221194110

Alric J (2010) Cyclic electron flow around photosystem I in unicellular green algae. Photosynth Res 106:47-56. https://doi.org/10.1007/ s11120-010-9566-4

Alric J, Johnson X (2017) Alternative electron transport pathways in photosynthesis: a confluence of regulation. Curr Opin Plant Biol 37:78-86. https://doi.org/10.1016/j.pbi.2017.03.014

Baalmann E, Backhausen JE, Rak C, Vetter S, Scheibe R (1995) Reductive modification and nonreductive activation of purified spinach chloroplast NADP-dependent glyceraldehyde-3-phosphate dehydrogenase. Arch Biochem Biophys 324:201-208

Baalmann E, Scheibe R, Cerff R, Martin W (1996) Functional studies of chloroplast glyceraldehyde-3-phosphate dehydrogenase subunits A and B expressed in Escherichia coli: formation of highly active A 4 and B 4 homotetramers and evidence that aggregation of the $\mathrm{B} 4$ complex is mediated by the $\mathrm{B}$ subunit carboxy terminus. Plant Mol Biol 32:505-513

Backhausen JE, Scheibe R (1999) Adaptation of tobacco plants to elevated $\mathrm{CO}_{2}$ : influence of leaf age on changes in physiology, redox states and NADP-malate dehydrogenase activity. J Exp Bot 50:665-675

Backhausen JE, Kitzmann C, Scheibe R (1994) Competition between electron acceptors in photosynthesis: regulation of the malate valve during $\mathrm{CO}_{2}$ fixation and nitrite reduction. Photosynth Res 42:75-86

Backhausen JE, Emmerlich A, Holtgrefe S, Horton P, Nast G, Rogers JJM, Müller-Röber B, Scheibe R (1998a) Transgenic potato plants with altered expression levels of chloroplast NADP-malate dehydrogenase: interactions between photosynthetic electron transport and malate metabolism in leaves and in isolated intact chloroplasts. Planta 207:104-114

Backhausen JE, Vetter S, Baalmann E, Kitzmann C, Scheibe R (1998b) NAD-dependent malate dehydrogenase and glyceraldehyde 3-phosphate dehydrogenase isoenzymes play an important role in dark metabolism of various plastid types. Planta 205:359-366

Backhausen JE, Kitzmann C, Horton P, Scheibe R (2000) Electron acceptors in isolated intact spinach chloroplasts act hierarchically to prevent over-reduction and competition for electrons. Photosynth Res 64:1-13 
Bailey-Serres J, Pierik R, Ruban A, Wingler A (2018) The dynamic plant: capture, transformation, and management of energy. Plant Physiol 176:961-966. https://doi.org/10.1104/pp.18.00041

Becker B, Holtgrefe S, Jung S, Wunrau C, Kandlbinder A, Baier M, Dietz KJ, Backhausen JE, Scheibe R (2006) Influence of the photoperiod on redox regulation and stress responses in Arabidopsis thaliana L. (Heynh.) plants under long- and short-day conditions. Planta 224:380-393. https://doi.org/10.1007/s00425-006-0222-3

Buchanan BB, Balmer Y (2005) Redox regulation: a broadening horizon. Annu Rev Plant Biol 56:187-220

Bussell JD, Keech O, Fenske R, Smith SM (2013) Requirement for the plastidial oxidative pentose phosphate pathway for nitrate assimilation in Arabidopsis. Plant J 75:578-591. https://doi. org/10.1111/tpj.12222

Bustos DM, Bustamante CA, Iglesias AA (2008) Involvement of non-phosphorylating glyceraldehyde-3-phosphate dehydrogenase in response to oxidative stress. Plant Physiol 165:456-461

Dietz KJ (2015) Efficient high light acclimation involves rapid processes at multiple mechanistic levels. J Exp Bot 66:2401-2414. https://doi.org/10.1093/jxb/eru505

Dietz KJ, Pfannschmidt T (2011) Novel regulators in photosynthetic redox control of plant metabolism and gene expression. Plant Physiol 155:1477-1485

Dietz KJ, Jacquot JP, Harris G (2010) Hubs and bottlenecks in plant molecular signalling networks. New Phytol 188:919-938

Dolferus R (2014) To grow or not to grow: a stressful decision for plants. Plant Sci 229:247-261. https://doi.org/10.1016/j.plant sci.2014.10.002

Escobar MA, Geisler DA, Rasmusson AG (2006) Reorganization of the alternative pathways of the Arabidopsis respiratory chain by nitrogen supply: opposing effects of ammonium and nitrate. Plant J 45:775-788

Faske M, Holtgrefe S, Ocheretina O, Meister M, Backhausen JE, Scheibe R (1995) Redox equilibria between the regulatory thiols of light/dark-modulated chloroplast enzymes and dithiothreitol: fine-tuning by metabolites. Biochim Biophys Acta 1247:135-142

Faske M, Backhausen JE, Sendker M, Singer-Bayrle M, Scheibe R, von Schaewen A (1997) Transgenic tobacco plants expressing pea chloroplast Nmdh cDNA in sense and antisense orientation Effects on NADP-malate dehydrogenase level, stability of transformants, and plant growth. Plant Physiol 115:705-715

Flügge UI, Heldt HW (1984) The phosphate-triose phosphate-phosphoglycerate translocator of the chloroplast. Trends Biochem Sci 9:530-533

Foyer CH, Noctor G (2011) Ascorbate and glutathione: the heart of the redox hub. Plant Physiol 155:2-18. https://doi.org/10.1104/ pp. 110.167569

Foyer CH, Ruban AV, Noctor G (2017a) Viewing oxidative stress through the lens of oxidative signalling rather than damage. Biochem J 474:877-883. https://doi.org/10.1042/BCJ20160814

Foyer CH, Ruban AV, Nixon PJ (2017b) Photosynthesis solutions to enhance productivity. Philos Trans R Soc Lond B Biol Sci 372. https://doi.org/10.1098/rstb.2016.0374

Gardeström P, Igamberdiev AU (2016) The origin of cytosolic ATP in photosynthetic cells. Physiol Plant 157:367-379. https://doi. org/10.1111/ppl.12455

Hameister S, Becker B, Holtgrefe S, Strodtkötter I, Linke V, Backhausen JE, Scheibe R (2007) Transcriptional regulation of NADPdependent malate dehydrogenase: comparative genetics and identification of DNA-binding proteins. J Mol Evol 65:437-455. doi:https://doi.org/10.1007/s00239-007-9025-9

Hancock JT, Henson D, Nyirenda M, Desikan R, Harrison J, Lewis M, Hughes J, Neill SJ (2005) Proteomic identification of glyceraldehyde 3-phosphate dehydrogenase as an inhibitory target of hydrogen peroxide in Arabidopsis. Plant Physiol Biochem 43:828-835. https://doi.org/10.1016/j.plaphy.2005.07.012

Hancock J, Desikan R, Harrison J, Bright J, Hooley R, Neill S (2006) Doing the unexpected: proteins involved in hydrogen peroxide perception. J Exp Bot 57:1711-1718

Hanke G, Scheibe R (2018) The contribution of electron transfer after photosystem I to balancing photosynthesis. In: Barber J, Ruban AV (eds) Photosynthesis and bioenergetics. World Scientific Publishing, Singapore, pp 277-303

Hansen LD, Breidenbach RW, Smith BN, Hansen JR, Criddle RS (1998) Misconceptions about the relation between plant growth and respiration. Bot Acta 111:255-260

Hara MR, Agrawal N, Kim SF, Cascio MB, Fujimuro M, Ozeki Y, Takahashi M, Cheah JH, Tankou SK, Hester LD, Ferris CD, Hayward SD, Snyder SH, Sawa A (2005) S-nitrosylated GAPDH initiates apoptotic cell death by nuclear translocation following Siah1 binding. Nat Cell Biol 7:665-674. https://doi.org/10.1038/ ncb1268

Hara S, Motohashi K, Arisaka F, Romano PG, Hosoya-Matsuda N, Kikuchi N, Fusada N, Hisabori T (2006) Thioredoxin-h1 reduces and reactivates the oxidized cytosolic malate dehydrogenase dimer in higher plants. J Biol Chem 281:32065-32071. https:// doi.org/10.1074/jbc.M605784200

Hebbelmann I, Selinski J, Wehmeyer C, Goss T, Voss I, Mulo P, Kangasjärvi S, Aro EM, Oelze ML, Dietz KJ, Nunes-Nesi A, Do PT, Fernie AR, Talla SK, Raghavendra AS, Linke V, Scheibe R (2012) Multiple strategies to prevent oxidative stress in Arabidopsis plants lacking the malate valve enzyme NADP-malate dehydrogenase. J Exp Bot 63:1445-1459. https://doi.org/10.1093/jxb/err386

Hildebrandt T, Knuesting J, Berndt C, Morgan B, Scheibe R (2015) Cytosolic thiol switches regulating basic cellular functions: GAPDH as an information hub? Biol Chem 396:523-537. https ://doi.org/10.1515/hsz-2014-0295

Hodges M, Dellero Y, Keech O, Betti M, Raghavendra AS, Sage R, Zhu XG, Allen DK, Weber AP (2016) Perspectives for a better understanding of the metabolic integration of photorespiration within a complex plant primary metabolism network. J Exp Bot 67:3015-3026. https://doi.org/10.1093/jxb/erw145

Holtgrefe S, Backhausen JE, Kitzmann C, Scheibe R (1997) Regulation of steady-state photosynthesis in isolated intact chloroplasts under constant light: responses of carbon fluxes, metabolic pools and enzyme-activation states to changes of electron pressure. Plant Cell Physiol 38:1207-1216

Holtgrefe S, Gohlke J, Starmann J, Druce S, Klocke S, Altmann B, Wojtera J, Lindermayr C, Scheibe R (2008) Regulation of plant cytosolic glyceraldehyde 3-phosphate dehydrogenase isoforms by thiol modifications. Physiol Plant 133:211-228. https://doi.org/1 0.1111/j.1399-3054.2008.01066.x

Huang J, Niazi AK, Young D, Rosado LA, Vertommen D, Bodra N, Abdelgawwad MR, Vignols F, Wei B, Wahni K, Bashandy T, Bariat L, Van Breusegem F, Messens J, Reichheld JP (2017) Self-protection of cytosolic malate dehydrogenase against oxidative stress in Arabidopsis. J Exp Bot 69:3491-3505. https://doi. org/10.1093/jxb/erx396

Jokel M, Johnson X, Peltier G, Aro EM, Allahverdiyeva Y (2018) Hunting the main player enabling Chlamydomonas reinhardtii growth under fluctuating light. Plant J 94:822-835. https://doi. org/10.1111/tpj.13897

Kerchev P, De Smet B, Waszczak C, Messens J, Van Breusegem F (2015) Redox strategies for crop improvement. Antioxid Redox Signal 23:1186-1205. https://doi.org/10.1089/ars.2014.6033

Klein P, Seidel T, Stocker B, Dietz KJ (2012) The membrane-tethered transcription factor ANAC089 serves as redox-dependent suppressor of stromal ascorbate peroxidase gene expression. Front Plant Sci 3:247. https://doi.org/10.3389/fpls.2012.00247 
Knuesting J, Scheibe R (2018) Small molecules govern thiol redox switches. Trends Plant Sci 23:769-782. https://doi.org/10.1016/j. tplants.2018.06.007

Kocsy G, Tari I, Vankova R, Zechmann B, Gulyás Z, Poór P, Galiba G (2013) Redox control of plant growth and development. Plant Sci 211:77-91. https://doi.org/10.1016/j.plantsci.2013.07.004

Kong F, Burlacot A, Liang Y, Légeret B, Alseekh S, Brotman Y, Fernie AR, Krieger-Liszkay A, Beisson F, Peltier G, Li-Beisson Y (2018) Interorganelle communicaton: peroxisomal malate dehydrogenase 2 connects lipid catabolism to photosynthesis through redox coupling in Chlamydomonas. Plant Cell. https://doi.org/10.1105/ tpc. 18.00361

Konishi N, Ishiyama K, Matsuoka K, Maru I, Hayakawa T, Yamaya T, Kojima S (2014) NADH-dependent glutamate synthase plays a crucial role in assimilating ammonium in the Arabidopsis root. Physiol Plant 152:138-151. https://doi.org/10.1111/ppl.12177

Kramer DM, Evans JR (2011) The importance of energy balance in improving photosynthetic productivity. Plant Physiol 155:70-78

Kromdijk J, Glowacka K, Leonelli L, Gabilly ST, Iwai M, Niyogi KK, Long SP (2016) Improving photosynthesis and crop productivity by accelerating recovery from photoprotection. Science 354(6314):857-861. https://doi.org/10.1126/science.aai8878

Krömer S, Heldt H-W (1991) On the role of mitochondrial oxidative phosphorylation in photosynthesis metabolism as studied by the effect of oligomycin on photosynthesis in protoplasts and leaves of barley (Hordeum vulgare). Plant Physiol 95:1270-1276

Landi S, Nurcato R, De Lillo A, Lentini M, Grillo S, Esposito S (2016) Glucose-6-phosphate dehydrogenase plays a central role in the response of tomato (Solanum lycopersicum) plants to short and long-term drought. Plant Physiol Biochem 105:79-89. https://doi. org/10.1016/j.plaphy.2016.04.013

Lee SM, Kim JH, Cho EJ, Youn HD (2009) A nucleocytoplasmic malate dehydrogenase regulates p53 transcriptional activity in response to metabolic stress. Cell Death Differ 16:738-748. https ://doi.org/10.1038/cdd.2009.5

Locato V, Cimini S, De Gara L (2018) ROS and redox balance as multifaceted players of cross-tolerance: epigenetic and retrograde control of gene expression. J Exp Bot 69:3373-3391. https://doi. org/10.1093/jxb/ery 168

Meyer Y, Siala W, Bashandy T, Riondet C, Vignols F, Reichheld JP (2008) Glutaredoxins and thioredoxins in plants. Biochim Biophys Acta 1783:589-600. https://doi.org/10.1016/j.bbamc r.2007.10.017

Mittler R (2016) ROS are good. Trends Plant Sci 22:11-19. https://doi. org/10.1016/j.tplants.2016.08.002

Møller IM (2001) Plant mitochondria and oxidative stress: electron transport, NADPH turnover, and metabolism of reactive oxygen species. Annu Rev Plant Physiol Plant Mol Biol 52:561-591

Oelze ML, Vogel MO, Alsharafa K, Kahman U, Viehhauser A, Maurino VG, Dietz KJ (2012) Efficient acclimation of the chloroplast antioxidant defence of Arabidopsis thaliana leaves in response to a 10- or 100-fold light increment and the possible involvement of retrograde signals. J Exp Bot 63:1297-1313

Peralta D, Bronowska AK, Morgan B, Doka E, Van Laer K, Nagy P, Grater F, Dick TP (2015) A proton relay enhances $\mathrm{H}_{2} \mathrm{O}_{2}$ sensitivity of GAPDH to facilitate metabolic adaptation. Nat Chem Biol 11:156-163. https://doi.org/10.1038/nchembio.1720

Peralta DA, Araya A, Busi MV, Gomez-Casati DF (2016) The E3 ubiquitin-ligase SEVEN IN ABSENTIA like 7 mono-ubiquitinates glyceraldehyde-3-phosphate dehydrogenase 1 isoform in vitro and is required for its nuclear localization in Arabidopsis thaliana. Int J Biochem Cell Biol 70:48-56. https://doi.org/10.1016/j.bioce 1.2015.11.007

Piattoni CV, Guerrero SA, Iglesias AA (2013) A differential redox regulation of the pathways metabolizing glyceraldehyde-3-phosphate tunes the production of reducing power in the cytosol of plant cells. Int J Mol Sci 14:8073-8092. https://doi.org/10.3390/ijms1 4048073

Podgórska A, Gieczewska K, Lukawska-Kuzma K, Rasmusson AG, Gardeström P, Szal B (2013) Long-term ammonium nutrition of Arabidopsis increases the extrachloroplastic NAD $(\mathrm{P}) \mathrm{H} / \mathrm{NAD}(\mathrm{P})$ $\left({ }^{+}\right)$ratio and mitochondrial reactive oxygen species level in leaves but does not impair photosynthetic capacity. Plant Cell Environ 36:2034-2045. https://doi.org/10.1111/pce.12113

Podgórska A, Ostaszewska M, Gardeström P, Rasmusson AG, Szal B (2015) In comparison with nitrate nutrition, ammonium nutrition increases growth of the frostbite1 Arabidopsis mutant. Plant Cell Environ 38:224-237. https://doi.org/10.1111/pce.12404

Podgórska A, Burian M, Rychter AM, Rasmusson AG, Szal B (2017) Short-term ammonium supply induces cellular defence to prevent oxidative stress in Arabidopsis leaves. Physiol Plant 160:65-83. https://doi.org/10.1111/ppl.12538

Pulido P, Spínola MC, Kirchsteiger K, Guinea M, Pascual MB, Sahrawy M, Sandalio LM, Dietz KJ, Gonzalez M, Cejudo FJ (2010) Functional analysis of the pathways for 2-Cys peroxiredoxin reduction in Arabidopsis thaliana chloroplasts. J Exp Bot 61:4043-4054. https://doi.org/10.1093/jxb/erq218

Raghavendra AS, Padmasree K (2003) Beneficial interactions of mitochondrial metabolism with photosynthetic carbon assimilation. Trends Plant Sci 8:546-553. https://doi.org/10.1016/j.tplan ts.2003.09.015

Rius SP, Casati P, Iglesias AA, Gomez-Casati DF (2006) Characterization of an Arabidopsis thaliana mutant lacking a cytosolic nonphosphorylating glyceraldehyde-3-phosphate dehydrogenase. Plant Mol Biol 61:945-957

Ruban AV, Johnson MP, Duffy CD (2012) The photoprotective molecular switch in the photosystem II antenna. Biochim Biophys Acta 1817:167-181. https://doi.org/10.1016/j.bbabio.2011.04.007

Scheibe R (1991) Redox-modulation of chloroplast enzymes A common principle for individual control. Plant Physiol 96:1-3

Scheibe R (2004) Malate valves to balance cellular energy supply. Physiol Plant 120:21-26

Scheibe R, Dietz KJ (2012) Reduction-oxidation network for flexible adjustment of cellular metabolism in photoautotrophic cells. Plant Cell Environ 35:202-216

Scheibe R, Stitt M (1988) Comparison of NADP-malate dehydrogenase activation, $Q_{A}$ reduction and $\mathrm{O}_{2}$ evolution in spinach leaves. Plant Physiol Biochem 26:473-481

Scheibe R, Backhausen JE, Emmerlich V, Holtgrefe S (2005) Strategies to maintain redox homeostasis during photosynthesis under changing conditions. J Exp Bot 56:1481-1489. https://doi. org/10.1093/jxb/eri181

Schneider M, Knuesting J, Birkholz O, Heinisch JJ, Scheibe R (2018) Cytosolic GAPDH as a redox-dependent regulator of energy metabolism. BMC Plant Biol. https://doi.org/10.1186/s1287 0-018-1390-6

Selinski J, Scheibe R (2014) Lack of malate valve capacities lead to improved $\mathrm{N}$-assimilation and growth in transgenic A. thaliana plants. Plant Signal Behav 9:e29057-e29051

Selinski J, Scheibe R (2018) Malate valves: old shuttles with new perspectives. Plant Biol. https://doi.org/10.1111/plb.12869

Selinski J, Hartmann A, Kordes A, Deckers-Hebestreit G, Whelan J, Scheibe R (2017) Analysis of posttranslational activation of alternative oxidase isoforms. Plant Physiol 174:2113-2127. https://doi. org/10.1104/pp.17.00681

Selinski J, Hartmann A, Deckers-Hebestreit G, Day DA, Whelan J, Scheibe R (2018a) Alternative oxidase isoforms are differentially activated by tricarboxylic acid cycle intermediates. Plant Physiol 176:1423-1432. https://doi.org/10.1104/pp.17.01331 
Selinski J, Scheibe R, Day DA, Whelan J (2018b) Alternative oxidase is positive for plant performance. Trends Plant Sci 23:588-597. https://doi.org/10.1016/j.tplants.2018.03.012

Selye H (1950) Stress and the general adaptation syndrome. BMJ $1: 1383-1392$

Shimakawa G, Ishizaki K, Tsukamoto S, Tanaka M, Sejima T, Miyake C (2017) The liverwort, Marchantia, drives alternative electron flow using a flavodiiron protein to protect PSI. Plant Physiol 173:1636-1647. https://doi.org/10.1104/pp.16.01038

Sirover MA (2011) On the functional diversity of glyceraldehyde3-phosphate dehydrogenase: biochemical mechanisms and regulatory control. Biochim Biophys Acta 1810:741-751

Steinbeck J, Nikolova D, Weingarten R, Johnson X, Richaud P, Peltier G, Hermann M, Magneschi L, Hippler M (2015) Deletion of proton gradient regulation 5 (PGR5) and PGR5-Like 1 (PGRL1) proteins promote sustainable light-driven hydrogen production in Chlamydomonas reinhardtii due to increased PSII activity under sulfur deprivation. Front Plant Sci 6:892. https://doi.org/10.3389/ fpls.2015.00892

Strodtkötter I, Padmasree K, Dinakar C, Speth B, Niazi PS, Wojtera J, Voss I, Do PT, Nunes-Nesi A, Fernie AR, Linke V, Raghavendra AS, Scheibe R (2009) Induction of the AOX1D isoform of alternative oxidase in A. thaliana T-DNA insertion lines lacking isoform AOX1A is insufficient to optimize photosynthesis when treated with antimycin A. Mol Plant 2:284-297

Sunil B, Talla SK, Aswani V, Raghavendra AS (2013) Optimization of photosynthesis by multiple metabolic pathways involving interorganelle interactions: resource sharing and ROS maintenance as the bases. Photosynth Res 117:61-71. https://doi.org/10.1007/ s11120-013-9889-z

Sweetlove LJ, Fernie AR (2013) The spatial organization of metabolism within the plant cell. Annu Rev Plant Biol 64:723-746. https ://doi.org/10.1146/annurev-arplant-050312-120233

Taniguchi M, Miyake H (2012) Redox-shuttling between chloroplast and cytosol: integration of intra-chloroplast and extra-chloroplast metabolism. Curr Op Plant Biol 15:252-260

Theis J, Schroda M (2016) Revisiting the photosystem II repair cycle. Plant Signal Behav 11:e1218587. https://doi.org/10.1080/15592 324.2016.1218587

van der Linde K, Gutsche N, Leffers HM, Lindermayr C, Müller B, Holfgrefe S, Scheibe R (2011) Regulation of plant cytosolic aldolase functions by redox-modifications. Plant Physiol Biochem 49:946-957

Vescovi M, Zaffagnini M, Festa M, Trost P, Schiavo FL, Costa A (2013) Nuclear accumulation of cytosolic glyceraldehyde-3-phosphate dehydrogenase in cadmium-stressed Arabidopsis roots. Plant Physiol 162:333-346. https://doi.org/10.1104/pp.113.215194

Voss I, Koelmann M, Wojtera J, Holtgrefe S, Kitzmann C, Backhausen JE, Scheibe R (2008) Knockout of major leaf ferredoxin reveals new redox-regulatory adaptations in Arabidopsis thaliana. Physiol Plant 133:584-598

Voss I, Sunil B, Scheibe R, Raghavendra AS (2013) Emerging concept for the role of photorespiration as an important part of abiotic stress response. Plant Biol 15:713-722. https://doi.org/10.111 1/j.1438-8677.2012.00710.x

Wang R, Okamoto M, Xing X, Crawford NM (2003) Microarray analysis of the nitrate response in Arabidopsis roots and shoots reveals over 1,000 rapidly responding genes and new linkages to glucose, trehalose-6-phosphate, iron, and sulfate metabolism. Plant Physiol 132:556-567. https://doi.org/10.1104/pp.103.021253

Wingler A, Lea PJ, Quick WP, Leegood RC (2000) Photorespiration: metabolic pathways and their role in stress protection. Philos Trans R Soc Lond B 355:1517-1529

Wojtera-Kwiczor J, Gross F, Leffers HM, Kang M, Schneider M, Scheibe R (2012) Transfer of a redox-signal through the cytosol by redox-dependent microcompartmentation of glycolytic enzymes at mitochondria and actin cytoskeleton. Front Plant Sci 3:284. https://doi.org/10.3389/fpls.2012.00284

Zachgo S, Hanke GT, Scheibe R (2013) Plant cell microcompartments: a redox-signaling perspective. Biol Chem 394:203-216. https:// doi.org/10.1515/hsz-2012-0284

Zaffagnini M, Fermani S, Calvaresi M, Orru R, Iommarini L, Sparla F, Falini G, Bottoni A, Trost P (2016) Tuning cysteine reactivity and sulfenic acid stability by protein microenvironment in glyceraldehyde-3-phosphate dehydrogenases of Arabidopsis thaliana. Antioxid Redox Signal 24:1-9. https://doi.org/10.1089/ars.2015.6417

Zhao Y, Luo L, Xu J, Xin P, Guo H, Wu J, Bai L, Wang G, Chu J, Zuo J, Yu H, Huang X, Li J (2018) Malate transported from chloroplast to mitochondrion triggers production of ROS and PCD in Arabidopsis thaliana. Cell Res 28:448-461. https://doi.org/10.1038/ s41422-018-0024-8 